\title{
Research on Network Public Opinion Governance of Government Emergencies Under the Background of Big Data
}

\author{
Yan Wang
}

\author{
Dalian Municipal Party School \\ E-mail $\square$ wy810402@163.com
}

\begin{abstract}
This paper introduces the situation of the network public opinion of emergencies in the era of big data, summarizes the effectiveness of the construction of the government's network public opinion governance mechanism of emergencies, analyzes the main existing problems of the network public opinion governance mechanism of emergencies, and puts forward suggestions for the improvement of the network public opinion guidance of emergencies in the era of big data.
\end{abstract}

Keywords: big data, emergency, public opinion, guide government.

\section{INTRODUCTION}

The world faces profound changes unseen in a century. China is in a period of unprecedented strategic opportunities. China's economic and social development faces many risks and challenges, and emergencies occur from time to time in various fields. These emergencies not only bring serious economic losses to the country and people, but also easily evolve into online public opinion events, which will seriously affect social security and harmony and stability.

In the context of the in-depth development of big data technology, improving the government's ability to manage online public opinions is an important guarantee to promote effective communication between the government and the public, maintain social security, harmony and stability, and also an important embodiment of the modernization of national governance.

\section{ANALYSIS OF NETWORK PUBLIC OPINION SITUATION OF EMERGENCIES IN THE ERA OF BIG DATA}

In the era of big data, social data is characterized by large amount of information and low data value density. Compared with the traditional online public opinion management mode, the characteristics of online public opinion about emergencies in the era of big data are mainly reflected in the following aspects:

\subsection{Public opinion ferments and spreads rapidly}

In March 2020, the China Internet Network Information Center (CNNIC) issued the 45th edition of the Statistical Report on Internet Development in China. By March 2020, China had 904 million Internet users, up 75.08 million from the end of 2018, and the Internet penetration rate reached 64.5 percent, up 4.9 percentage points from the end of 2018. The number of Internet users using mobile phones reached 897 million, which means 99.3 percent of all Internet users use mobile phones to access the Internet[1].

The increasing number of netizens shows that China's emerging social media has become the main platform for generating and spreading online public opinion. The frequent use and increasing dependence of Internet users on mobile phones will enable the parties involved in the event to quickly participate in the online public opinion of the event and freely express their opinions and opinions on various online social platforms, thus accelerating the generation and dissemination of online public opinion and expanding the scope of influence[5].

\subsection{The dynamic control of public opinion is difficult}

In the era of big data, the fragmentation of information transmission of emergency network public opinions is significant, and numerous rumors are often 
generated in the mass of data information. However, due to the different education status and growth status of each individual, they have different perspectives and evaluation starting points for emergencies. These public opinions cannot have strong reliability and authenticity, and it is difficult to distinguish the truth and falsehood of data information. Therefore, the network public opinion caused by emergencies brings various difficulties to government governance[6].

After the gradual adaptation and development in recent years, in view of the increasingly prominent new characteristics of emergency network public opinion and the complexity of governance, the government has done a lot of work in the governance of network public opinion, and achieved obvious results. However, the government still has some problems in the governance mechanism of network public opinion in emergencies.

\section{MAIN PROBLEMS STILL EXISTING IN THE GOVERNANCE MECHANISM OF NETWORK PUBLIC OPINION IN EMERGENCIES}

\subsection{Insufficient attention is still paid to online public opinions of emergencies, and the release of official authoritative information lags behind}

The early stages of network public opinion in dealing with emergencies, government on network public opinion monitor and analysis have been used traditional way of thinking about the problem of network public opinion of the era of large data, unaware of the large data of huge amounts of data information impact on public opinion, ignored the social platform of Internet users for network dependent and everyone is a function of journalists. The government is often in a passive position in the online public opinion of emergencies, so that the official authoritative information is often released behind and the response is not timely.

\subsection{The responsibilities of governance subjects of network public opinions are unclear}

The governance of emergency network public opinion needs the cooperation of multiple administrative departments. And the responsibilities of management are not always clearly delineated. In the event of an emergency, responsibilities are unclear and responsibilities are passed on to each other[3].

\subsection{Improper online public opinion control methods}

In some emergency happens, the government is actively to understand the spread of the new era of network public opinion characteristics, in the absence of clarity of the situation to direct intervention of network public opinion information, which is used more mandatory public opinion management means, such as delete, close the account, clean up the web, "banned, pin, in order to through this way to prevent the spread of Internet public opinion emergency and fermentation. However, facts have proved that such a heavy "blocking" and light "sparse" control method is absolutely unscientific, which will seriously reduce the credibility of the government.

\subsection{The early warning system of public opinion monitoring is not perfect}

China's current public opinion monitoring and early warning system is not perfect enough to control those false rumor information in the first time and to fully understand the overall situation of public opinion in emergencies in the first time. Although local governments at all levels have public opinion monitoring personnel, there is no unified early warning standard and code of conduct for public opinion monitoring.,

\section{SUGGESTIONS FOR IMPROVING THE MANAGEMENT OF ONLINE PUBLIC OPINIONS ON EMERGENCIES IN THE ERA OF BIG DATA}

\subsection{Strengthen the Party's leadership over public opinion work and firmly grasp the power of public opinion}

On the one hand, government agencies should adhere to the people-centered value orientation and effectively connect their work with the needs of the masses. Government departments respond to social demands and public voices in a timely manner, and form a good interaction between officials and the public in public opinion. The government grasps the initiative in the interaction. Government wants to make of open, inclusive, on the other hand, too much to cope with public opinion to control, can not be "blocked" blindly "prevention", for the release of some discontent set aside the necessary export, push official public opinion social public opinion and collision, the running-in, constantly promote the officer of the people in this way communication and mutual understanding, promote the height of the official games public opinion and public opinion fit, make people feel the satisfaction of respect and participate in public affairs.

(1) Improving the government spokesman system

The establishment of a complete government news spokesman system and the promotion of openness and transparency in government work are conducive to our proactive adaptation to the new changes in the international situation[2]. 


\section{(2) Cultivating "opinion leaders"}

Government should pay attention to training and guidance of "opinion leaders", cultivate active Internet users active and relevant authority, well-known experts and scholars in the field of star people, become well-known network emotion blogger "opinion leaders", at the same time, government agencies should reasonable use of other power of social resources, to actively guide the network public opinion.

(3) Strengthen the construction of official WeChat platform

In the era of big data, if the government wants to take the initiative in the guidance of online public opinion, it must keep up with the development of The Times and strengthen the construction of official government news websites and micro-platforms.

First, strengthen the authority and credibility of the government.

Second, strengthen the interaction between the government and netizens.

\subsection{Establish and improve the online public opinion monitoring mechanism for emergencies}

First of all, all the data collected in the daily monitoring process are saved, and these data are sorted and analyzed within a certain period of time to find the similarities between each data information, and pay attention to whether it is triggered by historical keywords through keyword filtering technology.

Second, in the emergency network public opinion monitoring system, realize data sharing among different departments

Third, relevant government departments should use the system to ensure the standardization of public opinion monitoring, clarify the work responsibilities of each department, avoid buck-passing among departments, and ensure the effective development of network public opinion guidance.

\subsection{Improve the linkage mechanism for responding to public opinion in emergencies}

First of all, it is necessary to improve the mechanism of emergency information release and establish a unified and efficient information and data sharing platform.

Second, a data linkage platform for the public should be established.

\subsection{Establish and improve the accountability mechanism for online public opinion in emergencies}

(1) Establish the effect evaluation index system of public opinion response ability

First, government should establish network public opinion governance evaluation index system. Second, government should introduce the introduction of third-party professional evaluation institutions. The government invites qualified professional third-party evaluation institutions to help the government conduct scientific and reasonable evaluation[4].

(2) Local governments in China must speed up the improvement of the system construction of "responsibility to post" and "responsibility to person".

(3) Carry out the form of online evaluation and accountability.

\section{CONCLUSION}

On the premise of introducing the situation of network public opinion in emergencies, this paper summarizes the effectiveness of the construction of the government's network public opinion governance mechanism for emergencies, and analyzes the main existing problems of the network public opinion governance mechanism for nergencies. Suggestion on the governance of large network public opinion are put forward from four aspects: strengthening the party's leadership of public opinion work, establishing network public opinion monitoring mechanism, public opinion response linkage mechanism and network public opinion responsibility investigation mechanism.

About author: Wang Yan (1981-), female, born in Huludao, Liaoning province,professor of Dalian Party School;Research interest: Emergency management.

Fund Project: periodical research results of the 2021 Liaoning Economic and Social Development Project (Project No. : 2011slqnkt-037) "Research on Urban Public Crisis Management in Liaoning Province under the background of smart City".

\section{REFERENCES}

[1] Huang Ling ling. Research on the governance mechanism of online public opinion on emergencies in the era of big data [D].Xiangtan University.2019.5

[2] Li Ling chao. Research on Government Monitoring of Online Public Opinion in Emergencies [D]. Shenyang Normal University. 2020.5 
[3] Niu Zhi xia. Research on Government Response to Public Emergencies on Network Public Opinion [D]. Changchun University of Technology.2019.6

[4] Ding Jun jie. Classic cases of Online public Opinion and Crisis management of Public Emergencies [M].Beijing: Central Party School Press, 2010.

[5] Gao Hong ling. Online Public Opinion and
Social Stability $[\mathrm{M}]$. Beijing: Xinhua Press, 2011.

[6] Zhang C X. Research on public opinion ecology and guidance of major public emergencies -Reflection on public opinion ecology and guidance based on the spread of COVID-19 [J].Shandong Social Sciences.2020.10 